\title{
Late Dislocation after Total Hip Arthroplasty
}

\author{
R.M.D Meek, MD, FRCS (Tr \& Orth); D.B. Allan, FRCS; G. McPhillips, PhD; \\ L. Kerr, PhD and C.R. Howie, FRCS (Tr \& Orth) \\ From the Scottish Arthroplasty Project
}

\begin{abstract}
Objectives: Instability after total hip arthroplasty is a troublesome complication. It commonly occurs in the first 3 postoperative months, but the risk continues over time. There are numerous treatment options, but they have relatively unpredictable outcomes. Numerous factors have been associated with dislocation, but research has mainly focused on the surgical ones. Epidemiological factors remain the subject of much debate. We aimed to establish the incidence of dislocation over time.
\end{abstract}

Methods: The Scottish National arthroplasty non-voluntary registry is based on SMROI records (Scottish Morbidity Record) data. We analyzed the Scottish National Arthroplasty Project to find patients' dislocation rates.

Results: There were 62,175 total hip arthroplasties performed from April 1989 to March 2004 with an annual incidence of dislocation of $0.9 \%$.We found no increase in the rate of dislocation after 2 years.

Conclusions: It appears there is no late increase in dislocation rate.

Level of Evidence: Prognostic study, level II-I (prospective study).

Keywords: Arthroplasty; Dislocation; Epidemiology; Hip

$\mathrm{T}$ otal hip arthroplasty (THA) is an extremely successful operation, relieving pain and restoring function. However, every operative intervention has potential complications. After aseptic loosening of the hip component, dislocation is the most common and problematic complication. ${ }^{1,2}$ The definition of THA dislocation is complete loss of contact between the femoral head and acetabular component, which usually requires intervention to reduce the prosthetic head into the acetabular component. There are a number of subsequent non-surgical and surgical management treatments. Dislocation may occur early (within 3 months) or late, and be single or recurrent. The literature concentrates on the effect of prosthetic components used and technique, particularly head size and surgical approach. ${ }^{3-11}$ Recently, it has been proposed that dislocation rates will increase in the late postoperative period in association with increasing wear and declining muscle function and mental ability. ${ }^{12}$
Our hypothesis was that there would be a late increase incidence of dislocation. Therefore, we aimed to establish the incidence of dislocation over time.

\section{Methods}

The Scottish National Arthroplasty Project has recorded more than 62,000 THAs from April 1989 to March 2004, which provides robust data for analysis. The cases collected in the Scottish National Arthroplasty Project represent a cohort of prospectively collected data from Scottish Morbidity Record (SMR01) forms (figure 1).

We determined the annual incidence of dislocation for up to 15 years from commencement of registry data collection. We also identified the age, gender, deprivation index (scale 1-5 based on post-code indicators of disadvantage), diagnoses (e.g., Parkinson's disease, stroke, femoral neck fractures, rheumatoid arthritis). 


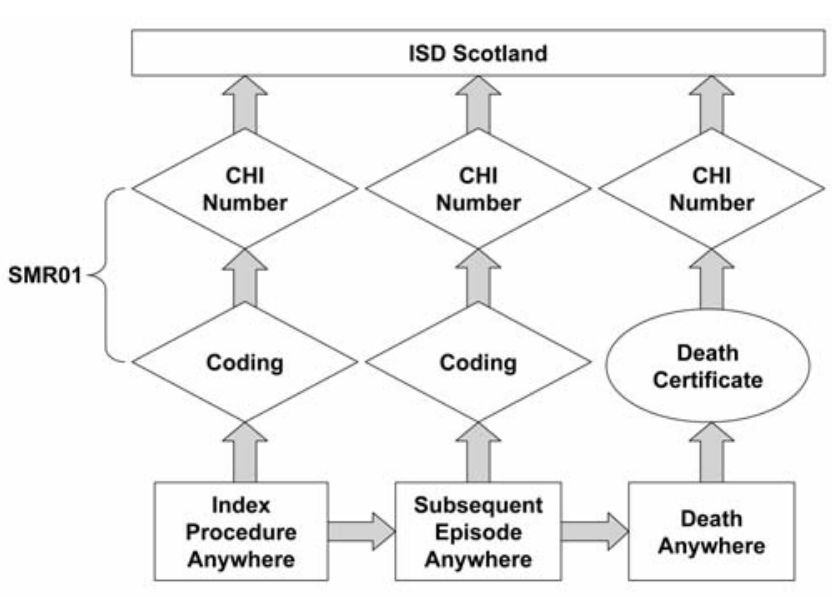

Figure 1. A flowchart showing the data for the Scottish Arthroplasty Project. The data are derived from the SMR01 (Scottish Morbidity Record). All National Health Service hospitals create an SMR01 record for every inpatient or day case episode, and every new episode creates a new SMR01 form. These are all collected at a central office and are linked with the General Register for Scotland death record.

All statistical analyses were performed by the Information and Statistics Division of the National Health Service of Scotland. Analyses were performed using the statistical package SPSS where appropriate t-test analysis was performed.

\section{Results}

There has been a gradual rise in the number of THAs per year (figure 2A), but with a gradual decrease in the absolute number of annual dislocations and rate (figures $2 \mathrm{~B}, 2 \mathrm{C}$ ). The most frequent age group to be operated on were patients 66 to 75 years, and the smallest group were patients older than 85 years (figure 3A). Patients older than 85 years had a higher incidence of dislocation but there has been a general downward trend for dislocation in all age groups over time (figure 3B).

Approximately 1000 (22\%) more THAs are performed on women than men each year, and this has remained fairly constant with time (figure 4A). There was no gender difference in the rate of annual dislocation and both genders displayed a reduced annual incidence over time (figure 4B).

We found no association between deprivation index (economic group) and rate of dislocation. However, there was an increased rate of dislocation $(P<0.0001)$ if the patient was not admitted from home.

There was a $5 \%$ to $8 \%$ range in annual incidence of patients with Parkinson's disease having a THA, and 2\% to $6 \%$ range in annual incidence of patients with a stroke having a THA (table 1). The number of dislocations per year for patients with Parkinson's disease and stroke was low with the annual rate of dislocation never above $1 \%$ (figures 5 and 6 ).
Patients who had a THA performed for femoral neck fracture had an increased $(P<0.0001)$ incidence $(>50 \%)$ of dislocation (table 2). Data from the registry also showed dislocation was associated $(P<0.0001)$ with the diagnosis of rheumatoid arthritis.

The post-operation timing of dislocation in the total 545 firsttime dislocations recorded from over 62,000 THAs over 12 years of registry data collection is shown in figure 7 . One hundred twenty-five of the $545(23 \%)$ occurred before 3 months. A further 234 (43\%) were from 3 to 12 months and a total of $359(66 \%)$ had dislocated by 1 year (table 3$)$. One hundred five dislocated between 1 and 2 years (19\%), but only a further $6 \%$ between 2 and 5 years.

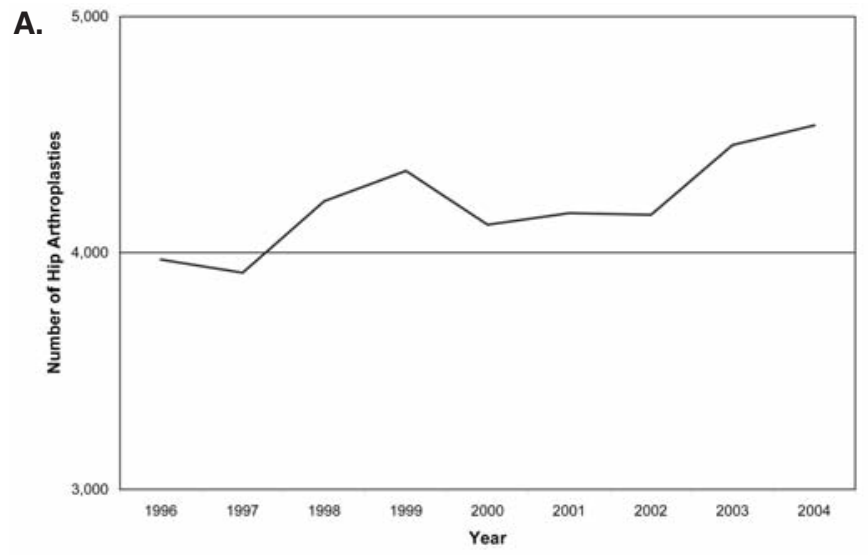

B.
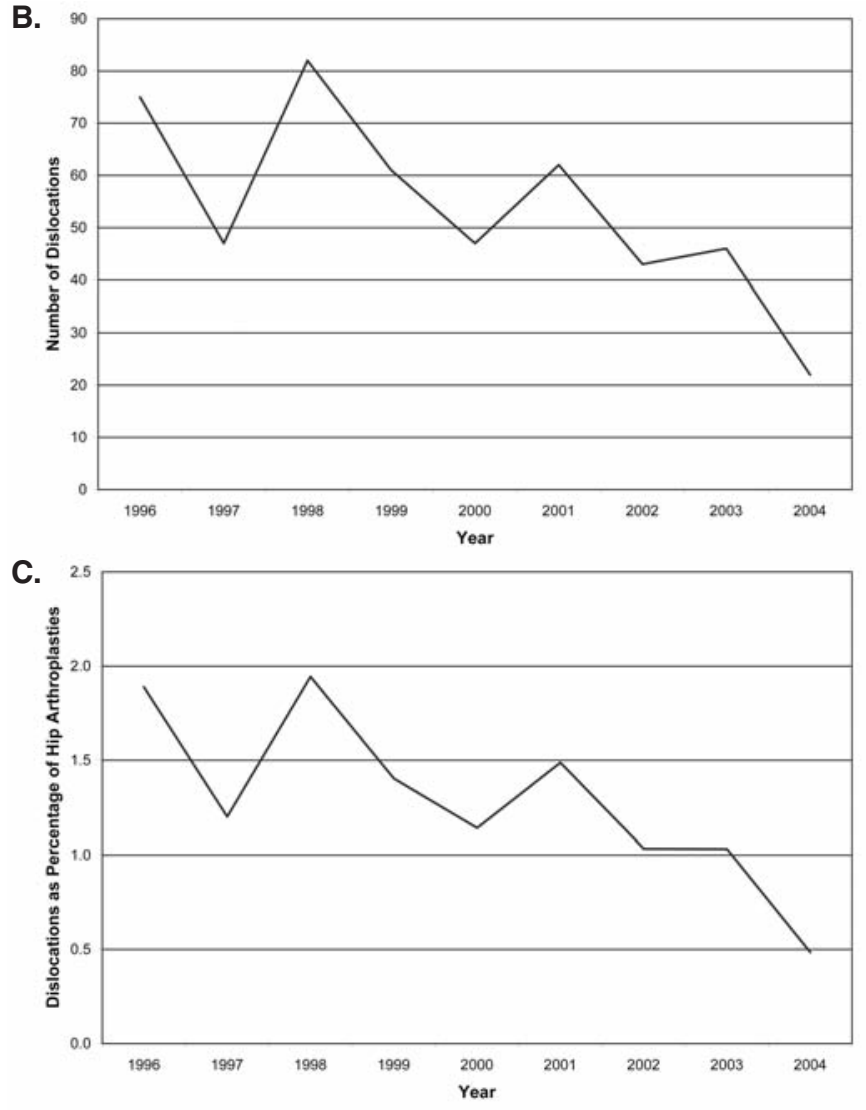

Figure 2. Number of THAs $(A)$ and dislocations $(B)$ per year from 1996 to 2004 to show a trend in annual dislocation rate (C). 
A.

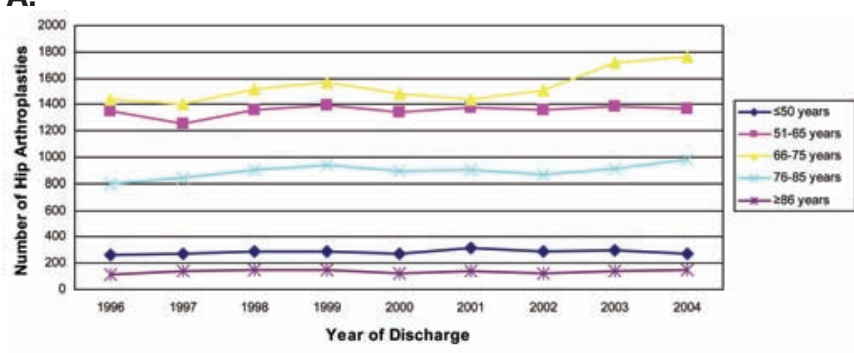

B.

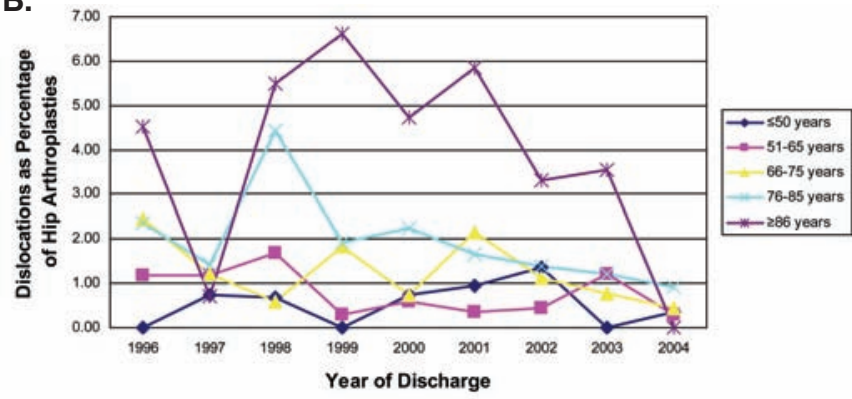

Figure 3. Number of THAs performed in each age group (A) and percentage by year discharged and age (B).

\section{Discussion}

We sought to establish the long-term dislocation risk and any associated demographic risk factors following THA in a registry that should capture full data using an administrative database. The Scottish National Arthroplasty Registry has the advantage of being non-voluntary and removes the potential bias of voluntary reporting and specialty center results. As with all arthroplasty registries, the large numbers allow statistical analysis and correlation of relatively rare associations. Our results showed that a variety of factors, including time of follow-up, is associated with the incidence of dislocation.

The limitations of this study are that the data collected did not include prosthesis type, surgical approach or level of surgeon experience. It is also dependent on the accuracy of the coding at the base hospital. Private hospitals in Scotland do not participate in the registry (we estimate this encompasses approximately $20 \%$ of arthroplasties performed in Scotland). Nevertheless, the Scottish National Arthroplasty Registry provides a robust audit of Scottish National Health Service practice.

The frequency of dislocation after THA is extremely variable. Surgeons usually advise patients of a $1 \%$ to $3 \%$ dislocation risk. The exact timing of this risk of dislocation is unclear. ${ }^{13-}$

15 Data from a population-based arthroplasty registry in the United Kingdom suggest a higher rate, 5\%, at 5 years postoperatively. ${ }^{16}$ These apparent variations may be due to differences between selected (expert) series and populationbased studies both with variable lengths and completeness of follow-up.

Hip arthroplasty dislocation can be divided into mechanical and clinical factors. ${ }^{9,14,15}$ Implant selection and surgical technique are predominately determined by preoperative planning and the intraoperative execution of implant positioning. Variables include femoral stem offset, acetabular version (and its relationship with stem anteversion), femoral head size selection (specifically head neck ratio and absolute size), and the presence of an acetabular augmentation or degree of constraint (cover). ${ }^{2-6,9,14,17-24}$ Malpositioning of components has been associated with late dislocation. 2,25 Surgical approach and soft tissue repair and tensioning has been emphasized as a key variable in determining dislocation rate. $8,10,11,23.26,27$ Padgett and Warashina ${ }^{28}$ report a similar review of these factors. Performing low numbers of procedures has been shown to have some effect on patient outcomes in several specialties. ${ }^{29-31}$ A previous report from the Scottish arthroplasty project highlighted that performing low numbers of procedures resulted in higher rates of dislocation. ${ }^{32}$

The incidence of dislocation reported here is in keeping with other reported rates. Encouragingly, the annual incidence has reduced over time. Our data does not provide us insight into why this is. However, one factor may be the annual feedback from the arthroplasty project to individual surgeons leading to outliers reviewing their practice. It is known that feedback leads to change, particularly those whose figures are outlying. ${ }^{33}$

Ekelund et $\mathrm{al}^{34}$ reported that age was related to dislocation, but not all reports found that correlation. ${ }^{13,15,22,25,35}$ Some reports have suggested that patients older than 80 years have a two- to three-fold increase in dislocation compared with younger patients. ${ }^{13,22}$ Brytröm et $\mathrm{al}^{4}$ reported that patients older than 80 years had a 4.5 times greater dislocation risk. Berry et $\mathrm{al}^{36}$ reported that the relative risk for dislocation in patients older than 70 years was $1.3 \%$. The results of the A.

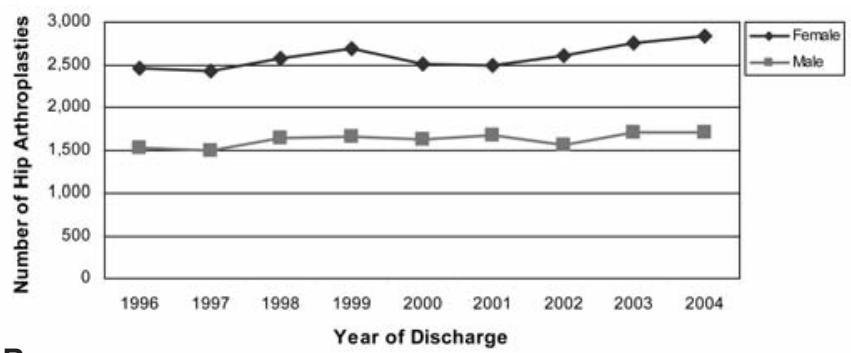

B.

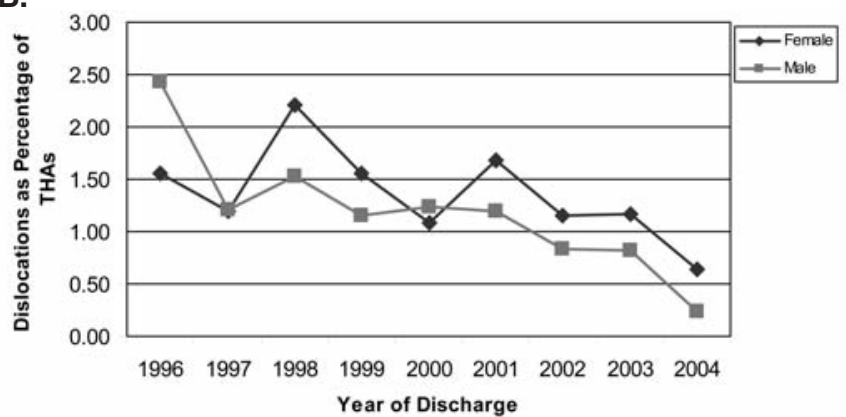

Figure 4. Gender distribution of THA recipients $(A)$ and percentage of dislocations by year and gender (B). 
Table 1. Year of discharge and percentage of patients with diagnoses of stroke or Parkinson's disease.

\begin{tabular}{|c|c|c|c|c|c|}
\hline \multicolumn{2}{|c|}{ Hip Arthoplasties } & \multicolumn{2}{|c|}{ Patients with stroke } & \multicolumn{2}{|c|}{ Patients with Parkinson's Disease } \\
\hline $\begin{array}{c}\text { Year } \\
\text { of discharge }\end{array}$ & $\mathbf{n}$ & $\mathbf{n}$ & $\%$ of arthroplasties & $\mathbf{n}$ & $\%$ of arthroplasties \\
\hline 1996 & 3970 & 277 & 6.98 & 230 & 5.79 \\
\hline 1997 & 3914 & 102 & 2.61 & 217 & 5.54 \\
\hline 1998 & 4218 & 141 & 3.34 & 264 & 6.26 \\
\hline 1999 & 4346 & 155 & 3.57 & 230 & 5.29 \\
\hline 2000 & 4118 & 148 & 3.59 & 312 & 7.58 \\
\hline 2001 & 4167 & 184 & 4.42 & 344 & 8.26 \\
\hline 2002 & 4160 & 226 & 5.43 & 311 & 7.48 \\
\hline 2003 & 4456 & 192 & 4.31 & 397 & 8.91 \\
\hline 2004 & 4539 & 222 & 4.89 & 401 & 8.83 \\
\hline
\end{tabular}

Scottish National Arthroplasty Registry are expected as there was a higher incidence of dislocation in patients older than 85 years. An encouraging feature was the downward trend in incidence of all dislocation rates, particularly in this elderly cohort. However, the reason for this is unclear. There may have been a trend to treat femoral neck fractures with THA from 1997-2001. There has been a trend to use larger femoral heads or constrained liners for elderly patients. Unfortunately the Scottish National Arthroplasty Registry does not collect prosthesis details (this is presently being added to the data set). Whether any increase in head size will produce a higher wear rate, and subsequent aseptic loosening rate, is unknown but may not be relevant in the older age group with the higher dislocation risk.

Several studies suggest female gender is a risk factor for dislocation. Some report ratios as high as $3: 1,4,15,36-40$ but not all report those differences. ${ }^{25,41}$ Our data did not show a gender difference and, reassuringly, both genders display a reduced annual incidence over time. This questions the hypothesis of a difference in tissue laxity. ${ }^{14}$ However, the duration of follow-up may affect the absolute rates because women live longer.

Jolles et $\mathrm{al}^{19}$ reported that when controlling for age, gender, pathology and year of surgery, a high American Association of Anesthesiologists score was associated with a 10-fold increased risk of dislocation. Hedlundh et $\mathrm{al}^{39}$ reported a higher mortality among the dislocating group. Mahomed et $\mathrm{al}^{41}$ used Medicare claims and found the 90-day dislocation rate to be $3.1 \%$ and that following multivariate analysis, this was associated with comorbidities and low income. Although the Scottish National Arthroplasty Registry is now collecting the American Association of Anesthesiologists information, there was insufficient data to confirm comorbidity as a factor; however there was no association with levels of deprivation.

Cognitive dysfunction from confusion, dementia, psychosis or alcoholism are reported as risk factors for hip instability. $25,39,42,43$ Woolson and Rahimtoola ${ }^{35}$ used regression analysis of dislocation in the first 3 months postoperatively and found cognitive dysfunction was a significant factor. Neuromuscular dysfunction has also been shown to have a positive association with dislocation. $13,25,39,44$ Loss of balance and sensitivity to vibration have also been reported as important factors. ${ }^{44}$ Our data demonstrate a surprisingly high rate of patients with THAs who have diagnoses of stroke $(4.3 \%$; range, $2.6 \%$ to $9.0 \%)$ or Parkinson's disease (7.1\%; range, 5.3\% to $8.9 \%)$. Despite a general belief that there is a higher rate of dislocation in such patients, there is very little literature to support this. Our results indicate that there is not a higher rate of dislocation in these patients. Perhaps drug therapy is sufficient to control neuromuscular imbalance. It suggests that surgeons should not be prejudiced against performing THA in patients diagnosed with stroke or Parkinson's disease.

Other clinical factors documented with an increased incidence of dislocation in the first 3 months postoperatively include previous surgery, acute fracture, trochanteric avulsion or proximal femur nonunion. $15,25,34,36,45,46$ Phillips et al ${ }^{47}$ analyzed Medicare claims data and reported a general 3.9\% incidence for primary THA and a $14.4 \%$ incidence for revision THA in the first 26 weeks postoperatively. This higher rate for revision THA has been suggested as being associated with more soft tissue dissections and trochanteric nonunions rather than different patient related factors. 48 Our data suggest that total hip arthroplasty after a previous

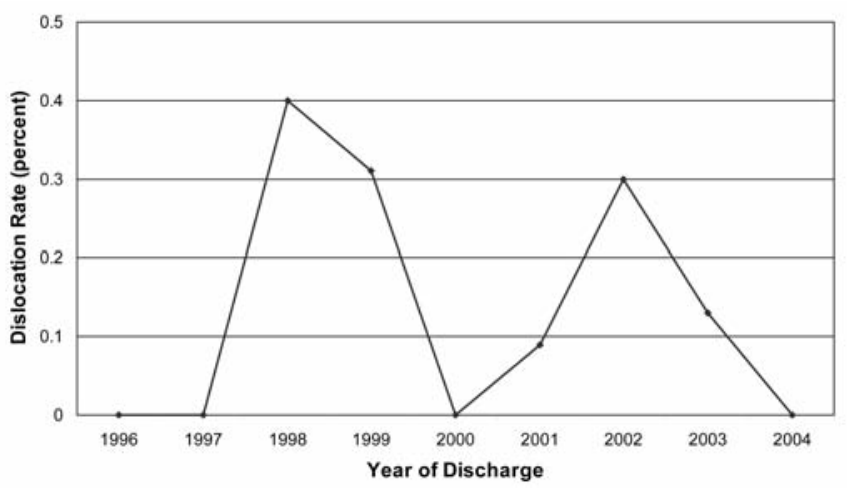

Figure 5. Dislocation rate by year for patients diagnosed with Parkinson's disease. 
Table 2. Dislocation rate for elective THA compared with THA for femoral neck fracture.

\begin{tabular}{lccc}
\hline Arthroplasty procedure & Dislocations (n) & Arthroplasties (n) & Dislocation rate (percent) \\
\hline Elective THA & 266 & 14,314 & 0.019 \\
THA for femoral neck fracture & 29 & 856 & 0.034 \\
\hline
\end{tabular}

THA, total hip arthroplasty.

femoral neck fracture does indeed have a higher incidence of dislocation. Some will be older patients with previous fixation or hemiarthroplasties. These represent a group of patients where more constrained prosthetic designs must be assessed versus patient comorbidity, the likelihood of prolonged survival and the need for THA revision for increased wear and osteolysis. Older patients may be offered a larger head articulation or constrained articulation. Younger patients may be considered for experimental bearings to avoid excessive wear such as highly cross-linked polyethylene, ceramic-on-ceramic or metal-on-metal to utilize larger diameter bearing couplings.

The diagnoses of osteoarthritis, the inflammatory arthropathy rheumatoid arthritis, avascular necrosis and developmental dysplasia of the hip have been reported as having no direct effect on dislocation rates as independent variables. ${ }^{13,25}$ However, inflammatory arthropathy has been reported as an independent risk factor for THA dislocation. ${ }^{43}$ In their prospective study, Zwartele et $\mathrm{al}^{43}$ assessed the incidence of

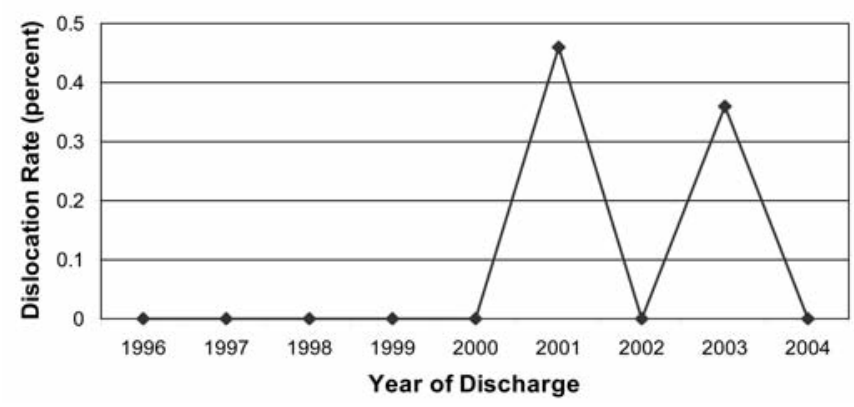

Figure 6. Dislocation rate by year for patients diagnosed with stroke.

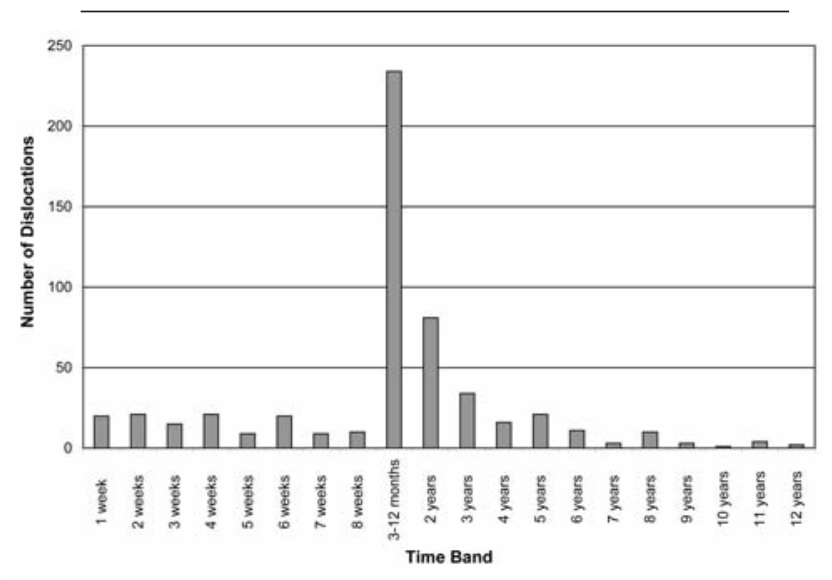

Figure 7. Number of dislocations for individual time periods following THA. dislocation within 2 years postoperatively for a cohort with inflammatory arthropathy and osteoarthritis. When controlling the confounders for prosthesis, age, prior hip surgery, surgeon experience and malpositioning of component, multilinear regression analysis demonstrated that inflammatory arthropathy had a higher incidence of dislocation (10\%) versus osteoarthritis (3\%) (odds ratio, 3.7; $95 \%$ confidence interval $[\mathrm{CI}], 1.3-11)$. This has also been supported by other reports. $11,36,45$ Osteonecrosis also has been associated with a greater risk of dislocation. ${ }^{36,45,46}$ There is no published evidence that ankylosing spondylitis has increased risk of dislocation, with reported rates comparable to standard series. ${ }^{40}$ Developmental dysplasia of the hip obviously represents a spectrum of severity. There are a variety of surgical treatments for patients with severe developmental dysplasia of the hip (Crowe grade 3 or 4). If a subtrochanteric osteotomy is performed, the incidence of dislocation is reportedly higher at $14 \%$ (3 of 21 patients). ${ }^{49}$ The Scottish National Arthroplasty Registry supports the results of increased dislocation in patients with rheumatoid arthritis. ${ }^{43}$

Most surgeons warn patients to undertake hip precautions for the first 3 months after their operation. Only $23 \%$ of all the dislocations occurred in this time period and a further $40 \%$ occurred during the 3 to 12 months postoperatively. It may be that patients should be warned that the risk of dislocation remains for the first year.

The time periods of index surgery may also be related to dislocation rates and not always with improvements. Brytröm et $\mathrm{al}^{4}$ reported a higher risk of dislocation during 1996-2000 than during 1987-1990 for Charnley hip replacements. This may be related to other factors, such as an increasing trend to operate on displaced femoral neck fractures, but it does demonstrate the necessity of patient follow-up to explain this.

The postoperative time of dislocation is important to determine and compare as the absolute risk of dislocation is not constant over time and a previous report suggested it was cumulative. ${ }^{36,46}$ A multivariate analysis reporting the effects of demographics on the long-term risk of dislocation as a function of time for the Charnley hip replacement reported a cumulative risk much greater than the early short-term reports with a $1 \%$ risk at 1 month postoperatively, $1.9 \%$ at 1 year postoperatively, a constant $1 \%$ increase every 5 years, and a $7 \%$ risk at 25 years. ${ }^{36}$ Therefore, a very long-term follow-up evaluation is necessary to determine the true frequency of 
Table 3. Distribution of initial dislocation presentation with time of follow-up.

\begin{tabular}{cc}
\hline Time band & Number of dislocations \\
\hline 1 week & 20 \\
2 weeks & 21 \\
3 weeks & 15 \\
4 weeks & 21 \\
5 weeks & 9 \\
6 weeks & 20 \\
7 weeks & 9 \\
8 weeks & 10 \\
$3-12$ months & 234 \\
2 years & 81 \\
3 years & 34 \\
4 years & 16 \\
5 years & 21 \\
6 years & 11 \\
7 years & 3 \\
8 years & 10 \\
9 years & 3 \\
10 years & 1 \\
11 years & 4 \\
12 years & 2 \\
\hline
\end{tabular}

dislocation, since late dislocation (over 5 years) has been suggested as a potential problem due to polyethylene wear and implant impingement. ${ }^{12}$ However, only 55 out of the 545 dislocations (10\%) recorded in the Scottish arthroplasty registry occurred 5 years or more after the index operation. There has been no sudden increased rate of late dislocations from 5 to 12 years in our population.

\section{Conclusion}

Elderly patients (age greater than 85) and a previous diagnosis of trauma or rheumatoid arthritis have a higher relative risk of dislocation. The majority of dislocations occur by 12 months (66\%). However, patients remain at relatively high risk even after the first 3 postoperative months by which time only $23 \%$ of the total dislocations have occurred. We have observed no late sudden increase in late dislocation rates. We suggest that published dislocation rates are standardized at 12 months post-surgery, accepting that a further third will develop over time. Continued follow-up of this will be reported by the Scottish National Arthroplasty Project.

\section{References}

1. Lindberg HO, Carlsson AS, Gentz CF, Pettersson H. Recurrent and non-recurrent dislocation following total hip arthroplasty. Acta Orthop Scand 1982;53:947-952.

2. Vaughn BK. Managing chronic dislocated total hip arthroplasty. Semin Arthroplasty 1993;4:16-24.

3. Bartz RL, Nobel PC, Kadakia NR, Tullos HS. The effect of femoral component head size on posterior dislocation of the artificial hip joint. The effect of femoral component head size on posterior dislocation of the artificial hip joint. J Bone Joint Surg Am 2000;82:1300-1307.
4. Byström S, Espehaug B, Furnes O, Havelin LI; Norwegian Arthroplasty Register. Femoral head size is a risk factor for total hip luxation: a study of 42,987 primary hip arthroplasties from the Norwegian Arthroplasty Register. Acta Orthop Scand 2003;74:514-524.

5. Cobb TK, Morrey BF, Ilstrup DM. The elevated-rim acetabular liner in total hip arthroplasty: relationship to postoperative dislocation. J Bone Joint Surg Am 1996;78:80-86.

6. Kelley SS, Lachiewicz PF, Hickman JM, Paterno SM. Relationship of femoral head and acetabular size to the prevalence of dislocation. Clin Orthop Relat Res 1998;(355):163-170.

7. Nicholas RM, Orr JF, Mollan RA, Calderwood JW, Nixon JR, Watson P. Dislocation of total hip replacements. A comparative study of standard, long posterior wall and augmented acetabular components. J Bone Joint Surg Br 1990;72:418-422.

8. Pellicci PM, Bostrom M, Poss R. Posterior approach to total hip replacement using enhanced posterior soft tissue repair. Clin Orthop Relat Res 1998;(355):224-228.

9. Robbins GM, Masri BA, Garbuz DS, Greidanus N, Duncan CP. Treatment of hip instability. Orthop Clin North Am 2001;32:593-610, viii.

10. Suh KT, Park BG, Choi YJ. A posterior approach to primary total hip arthroplasty with soft tissue repair. Clin Orthop Relat Res 2004;(418):162-167.

11. van Stralen GM, Struben PJ, van Loon CJ. The incidence of dislocation after primary total hip arthroplasty using posterior approach with posterior soft-tissue repair. Arch Orthop Trauma Surg 2003;123:219-222.

12. Parvizi J, Wade FA, Rapuri V, Springer BD, Berry DJ, Hozack WJ. Revision hip arthroplasty for late instability secondary to polyethylene wear. Clin Orthop Relat Res 2006;447:66-69.

13. Morrey BF. Instability after total hip arthroplasty. Orthop Clin North Am 1992;23:237-248.

14. Sanchez-Sotelo J, Berry DJ. Epidemiology of instability after total hip replacement. Orthop Clin North Am 2001;32:543552, vii.

15. Woo RY, Morrey BF. Dislocations after total hip arthroplasty. J Bone Joint Surg Am 1982;64:1295-1306.

16. Fender D, Harper WM, Gregg PJ. Outcome of Charnley total hip replacement across a single health region in England: the results at five years from a regional hip register. J Bone Joint Surg Br 1999;81:577-581.

17. André S, Feuilhade de Chauvin P, Tiberi F, Postel M. Luxations of the Charnley type and Kerboull-modified Charnley-type total prostheses. Rev Chir Orthop Reparatrice Appar Mot 1983;69:447-453.

18. Etienne A, Cupic Z, Charnley J. Postoperative dislocation after Charnley low-friction arthroplasty. Clin Orthop Relat Res 1978;(132):19-23.

19. Jolles BM, Zangger P, Leyvraz PF. Factors predisposing to dislocation after primary total hip arthroplasty: a multivariate analysis. J Arthroplasty 2002; 17:282-288.

20. Losina E, Barrett J, Mahomed NN, Baron JA, Katz JN. Early failures of total hip replacement: effect of surgeon volume. Arthritis Rheum 2004;50:1338-1343.

21. McAuley JP, Ridgeway SR. Preoperative planning to prevent dislocation of the hip. Orthop Clin North Am 2001;32: 579-586, viii.

22. Morrey BF. Difficult complications after hip joint replacement. Dislocation. Clin Orthop Relat Res 1997;(344):179-187.

23. Ranawat CS, Maynard MJ, Deshmukh RG. Cemented primary total hip arthroplasty. In: Sledge C, ed. Master Techniques in orthopaedic surgery: The hip. Philadelphia, PA: LippincottRaven;1998. 217-238. 
24. Scifert CF, Brown TD, Pedersen DR, Callaghan JJ. A finite element analysis of factors influencing total hip dislocation. Clin Orthop Relat Res 1998;(355):152-162.

25. Paterno SA, Lachiewicz PF, Kelley SS. The influence of patient-related factors and the position of the acetabular component on the rate of dislocation after total hip replacement. J Bone Joint Surg Am 1997;79:1202-1210.

26. Turner RS. Postoperative total hip prosthetic femoral head dislocations. Incidence, etiologic factors, and management. Clin Orthop Relat Res 1994;(301):196-204.

27. Weeden SH, Paprosky WG, Bowling JW. The early dislocation rate in primary total hip arthroplasty following the posterior approach with posterior soft-tissue repair. J Arthroplasty 2003;18:709-713.

28. Padgett DE, Warashina $\mathrm{H}$. The unstable total hip replacement. Clin Orthop Relat Res 2004;(420):72-79.

29. Birkmeyer JD, Stukel TA, Siewers AE, Goodney PP, Wennberg DE, Lucas FL. Surgeon volume and operative mortality in the United States. N Engl J Med 2003;349:2117-2127.

30. Carter D. The surgeon as a risk factor. BMJ 2003;326:832-833.

31. Kizer K. The volume-outcome conundrum. N Engl J Med 2003;349:2159-2161.

32. Scottish Arthroplasty Project: Annual Report May 2003. Scottish Arthroplasty Project Web site. Available at: http://www.arthro.scot.nhs.uk/Reports/Scottish_Arthroplasty_ Report_2003.pdf. Accessed November 30, 2007.

33. Fidler H, Lockyer JM, Toews J, Violato C. Changing physicians' practices: the effect of individual feedback. Acad Med 1999;74:702-714.

34. Ekelund A, Rydell N, Nilsson OS. Total hip arthroplasty in patients 80 years of age and older. Clin Orthop Relat Res 1992;(281):101-106.

35. Woolson ST, Rahimtoola ZO. Risk factors for dislocation during the first 3 months after primary total hip replacement. J Arthroplasty 1999;14:662-668.

36. Berry DJ, von Knoch M, Schleck CD, Harmsen WS. The cumulative long-term risk of dislocation after primary Charnley total hip arthroplasty. J Bone Joint Surg Am 2004;86-A:9-14.

37. Coventry MB. Late dislocations in patients with Charnley total hip arthroplasty. J Bone Joint Surg Am 1985;67:832-841.

38. Ali Khan MA, Brakenbury PH, Reynolds IS. Dislocation following total hip replacement. J Bone Joint Surg Br 1981;63-B:214-218

39. Hedlundh U, Fredin H. Patient characteristics in dislocations after primary total hip arthroplasty. 60 patients compared with a control group. Acta Orthop Scand 1995;66:225-228.

40. Tang WM, Chiu KY. Primary total hip arthroplasty in patients with ankylosing spondylitis. J Arthroplasty 2000;15:52-58.

41. Mahomed NN, Barrett JA, Katz JN, Phillips CB, Losina E, Lew RA, Guadagnoli E, Harris WH, Poss R, Baron JA. Rates and outcomes of primary and revision total hip replacement in the United States medicare population. J Bone Joint Surg Am 2003;85-A:27-32.

42. Espehaug B, Havelin LI, Engesaeter LB, Langeland N, Vollset SE. Patient-related risk factors for early revision of total hip replacements. A population register-based case-control study of 674 revised hips. Acta Orthop Scand 1997;68:207-215.

43. Zwartelé RE, Brand R, Doets HC. Increased risk of dislocation after primary total hip arthroplasty in inflammatory arthritis: a prospective observational study of 410 hips. Acta Orthop Scand 2004;75:684-690.

44. Hedlundh U, Karlsson M, Ringsberg K, Besjakov J, Fredin H. Muscular and neurologic function in patients with recurrent dislocation after total hip arthroplasty: a matched controlled study of 65 patients using dual-energy X-ray absorptiometry and postural stability tests. J Arthroplasty 1999;14:319-325.
45. Berry DJ. Unstable total hip arthroplasty: detailed overview. Instr Course Lect 2001;50:265-274.

46. Mabry TM, Prpa B, Haidukewych GJ, Harmsen WS, Berry DJ. Long-term results of total hip arthroplasty for femoral neck fracture nonunion. J Bone Joint Surg Am 2004;86-A: 2263-2267.

47. Phillips CB, Barrett JA, Losina E, Mahomed NN, Lingard EA, Guadagnoli E, Baron JA, Harris WH, Poss R, Katz JN. Incidence rates of dislocation, pulmonary embolism, and deep infection during the first six months after elective total hip replacement. J Bone Joint Surg Am 2003;85-A:20-26.

48. Alberton GM, High WA, Morrey BF. Dislocation after revision total hip arthroplasty: an analysis of risk factors and treatment options. J Bone Joint Surg Am 2002;84-A: 1788-1792.

49. Masonis JL, Patel JV, Miu A, Bourne RB, McCalden R, Macdonald SJ, Rorabeck CH. Subtrochanteric shortening and derotational osteotomy in primary total hip arthroplasty for patients with severe hip dysplasia: 5-year follow-up. J Arthroplasty 2003;18:68-73.

Author Affiliations

R.M.D Meek, MD, FRCS (Tr \& Orth)

Orthopaedic Department

Southern General Hospital

Glasgow, United Kingdom

D.B. Allan, FRCS

Orthopaedic Department

Southern General Hospital

Glasgow, United Kingdom

G. McPhillips, PhD

Royal College of Surgeons

Edinburgh, United Kingdom

L. Kerr, $P h D$

Royal College of Surgeons

Edinburgh, United Kingdom

C.R. Howie, FRCS (Tr \& Orth)

Royal Infirmary Edinburgh

Little France, Edinburgh, United Kingdom 